Int. J. Dev. Biol. 58: 273-280 (2014)

doi: $10.1387 / \mathrm{ijdb} .130329 \mathrm{gd}$

\title{
Pregnancy-specific glycoproteins: complex gene families regulating maternal-fetal interactions
}

\author{
TOM MOORE ${ }^{1}$ and GABRIELA S. DVEKSLER ${ }^{*, 2}$ \\ ${ }^{1}$ School of Biochemistry and Cell Biology, Western Gateway Building, University College Cork, Cork, Ireland and \\ ${ }^{2}$ Department of Pathology, Uniformed Services University of the Health Sciences, Bethesda, Maryland, USA
}

\begin{abstract}
The pregnancy-specific glycoproteins (PSGs) are the most abundant trophoblastic proteins in maternal blood during human pregnancy and they appear to be exclusive to species with hemochorial placentation. There are ten protein-coding human PSG genes (PSG1 - PSG9, PSG11) and also multiple PSG genes in non-human primates, rodents and bats. Several studies indicate that PSGs have immunoregulatory, pro-angiogenic, and anti-platelet functions. Some PSGs have been shown to bind different moieties on the surface of cells, including the tetraspanin CD9, heparan sulphate, and specific integrins. Recently, PSG1 was shown to associate with and activate the anti-inflammatory cytokines transforming growth factor (TGF)- $\beta 1$ and TGF- $\beta 2$ making PSG1 one of the few known biological activators of these important cytokines. TGF- $\beta$ s regulate many biological processes essential for pregnancy success including trophoblast invasion and proliferation, angiogenesis, extracellular matrix formation and tolerance to the fetal semi-allograft. As summarized in this review, progress has been made in recent years towards a better understanding of the functions of these proteins which were originally described in the early 1970s, but more research will likely contribute to demonstrate their importance for a successful pregnancy.
\end{abstract}

KEY WORDS: trophoblast, placental hormone, immunoregulation, TGF $\beta$, integrin

\section{Introduction}

The Pregnancy-specific glycoprotein (PSG) and the closely related Carcinoembryonic antigen cell adhesion molecule (CEACAM) gene families are members of the immunoglobulin $(I g)$ superfamily (Kammerer \& Zimmermann, 2010). The CEACAM/PSG ancestral gene is thought to be common to both primates and rodents, but subsequent gene duplications led to considerable diversification of protein structure, expression and function (Kammerer \& Zimmermann, 2010, Rudert et al., 1992). The CEACAMs are predominately cell membrane-anchored proteins whereas all PSGs are secreted (Kammerer \& Zimmermann, 2010). However, CEACAMs and PSGs share several structural features. Both CEACAMs and PSGs are encoded by multigene families and both families of proteins have an amino terminal Ig variable-like domain and a variable number of $\mathrm{lg}$ constant-like domains (Kammerer \& Zimmermann, 2010, McLellan et al., 2005a, Rudert et al., 1992). There are twelve human and fifteen mouse CEACAMgenes that are widely expressed in normal and cancerous tissues (Hammarstrom, 1999, Kuespert et al., 2006, Zebhauser et al., 2005). Structural and functional analyses indicate that CEACAM extracellular domains are involved in homotypic and heterotypic adhesion, and the cytoplasmic domains are involved in signal transduction(Huang et al., 2013, Kammerer \& Zimmermann, 2010, Obrink, 1997). By virtue of their expression on epithelia and immune cells, CEACAM family members act as pathogen receptors, which may be a significant influence on CEACAM family evolution (Chang et al., 2013, Kammerer \& Zimmermann, 2010). There are ten and seventeen PSG protein-coding genes in human and mouse, respectively (Kammerer \& Zimmermann, 2010, McLellan et al., 2005a). The phylogenetic distribution and expression of PSGs is more restricted than CEACAMs, and the evolutionary selective pressures driving PSG family expansion and diversification therefore may be different to CEACAMs (Ball et al., 2004, McLellan et al., 2005a, Wynne et al., 2006, Zhou et al., 1997).

\section{PSG locus, gene and protein structure}

The PSG genes are clustered at chromosome $19 q 13$ in the human and on proximal chromosome 7 in the mouse. The ten protein-

Abbreviations used in this paper: CEACAM, carcinoembryonic antigen cell adhesion molecule; PSG, pregnancy-specific glycoprotein; TGF, transforming growth factor.

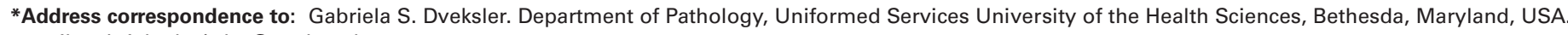
e-mail: gabriela.dveksler@usuhs.edu
}

Final, author-corrected PDF published online: 8 July 2014.

ISSN: Online 1696-3547, Print 0214-6282 
coding human PSG genes, PSG1 - PSG9, and PSG11 (PSG10 is a non-coding pseudogene), are arrayed within a genomic region of $0.55 \mathrm{Mb}$ (www.ensembl.org, Teglund et al., 1994). The mouse locus is approximately $1.74 \mathrm{Mb}$ and contains six Psg genes in the A2 chromosome band and eleven genes in the A3 band, the latter flanked by the unrelated Mill1 and Mill2 genes; we note that the gene order in the Psg locus described in McLellan et al., (2005a) is inaccurate and the correct map is available at www.ensembl.org. Human and mouse loci contain a variety of CEACAM and PSG pseudogenes and non-coding RNAs (Kammerer \& Zimmermann, 2010, www.ensembl.org). Orthologous relationships cannot be determined between human and mouse PSG genes indicating that these gene clusters have evolved independently since the common ancestor (McLellan et al., 2005a), although orthologous relations can be determined for a subset of mouse and rat PSGs (T. Moore \& colleagues, unpublished). The human PSG genes appear to exhibit a high level of copy number variations, rapid coding sequence divergence, and a relatively high frequency of gene conversion between different $P S G$ family members compared to the genome average (Chang et al., 2013, Dumont \& Eichler, 2013).

The domain organization of the human and mouse PSG proteins exhibit pronounced divergence (see Fig. 1). Human PSGs contain one Ig variable-like domain $(\mathrm{N})$ and, usually, three Ig constant-like domains (Ig C2-like domains of type A or B), and a relatively hy-
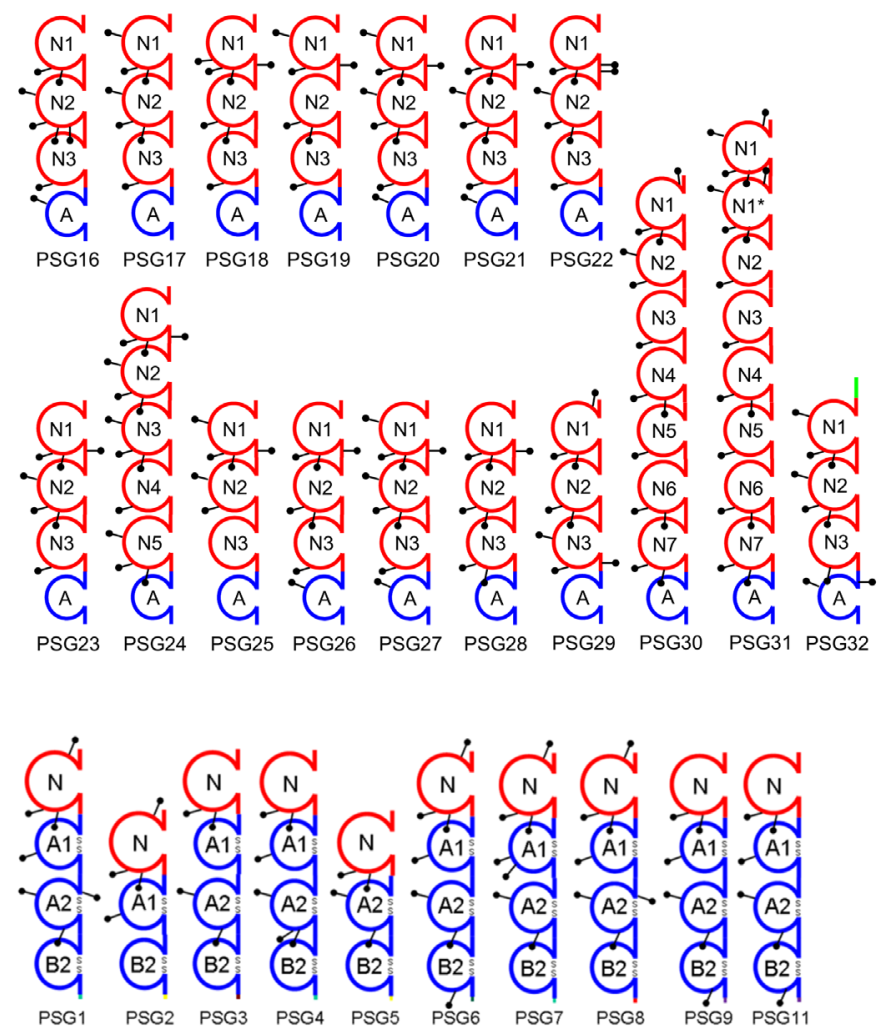

Fig. 1. Structures of mouse (PSG16 - PSG32) and human (PSG1 PSG9, PSG11) PSG proteins. (Adapted from McLellan et al., 2005, and http://Www.carcinoembryonic-antigen.de/index.html). Red color-coded ' $N$ ' domains are lg variable-like domains, and blue ' $A$ ' and ' $B$ ' domains are Ig constant-like domains. Black 'lollipops' indicate potential N-linked glycosylation sites. Note that atypical amino and carboxy terminal sequences are also color-coded. drophilic tail (www.carcinoembryonic-antigen.de, McLellan et al., 2005a). In addition, there are a number of variations, including splice variants, particularly at the carboxy terminus. However, many of these are poorly characterised and may reflect cloning and annotation of rare, functionally irrelevant variants. In contrast, rodent PSGs typically have three or more $\mathrm{Ig}$ variable-like $(\mathrm{N})$ domains followed by a single Ig constant-like (A) domain (McLellan et al., 2005). All eight rat PSGs, with the exception of PSG36 (N1-N2-N3-N4-N5A), are of the N1-N2-N3-A domain arrangement (McLellan et al., 2005b). The mouse Psg protein family has seventeen members, fourteen with three $\mathrm{N}$-domains and a single A-domain (N1-N2N3-A) arrangement, and three - Psg24, Psg30 and Psg31, which have an expanded structure created by domain duplications, as follows: Psg24 (N1-N2-N3-N4-N5-A), Psg30 (N1-N2-N3-N4-N5-N6N7-A) and Psg31 which has a recently duplicated N1 domain and therefore a (N1-N1-N2-N3-N4-N5-N6-N7-A) domain arrangement (McLellan et al., 2005a). However, notwithstanding these structural differences, there is evidence that human PSG N-domains and mouse N1-domains have conserved structures as evidenced by branching of the mouse N1-domains with human N-domain, in preference to mouse N2 and N3-domains, in a phylogenetic tree (McLellan et al., 2005b). This is consistent with the apparently conserved functions of human and mouse PSG proteins in immune and vascular regulation (see below). The common ancestor of human and mouse CEACAMs and PSGs was most likely similar to CEACAM1, the only family member with a homologous gene structure in the human, rat and mouse that encodes all types of extracellular domains present in CEACAM and PSG proteins (McLellan et al., 2005a, Rudert et al., 1992, Teglund et al., 1995).

\section{PSG expression pattern}

PSGs may be the most abundant trophoblastic proteins in maternal blood during human pregnancy. The maternal serum level increases as gestation progresses with concentrations of up to 200-400 $\mu \mathrm{g} / \mathrm{ml}$ reported at term, far exceeding levels of other wellknown placental hormones such as human chorionic gonadotropin (Lee et al., 1979, Lin et al., 1974, Towler et al., 1976). Mouse Psg proteins do not appear to exhibit similarly high levels of expression (J. Baensinger, Pers. Commun.). In the first half of mouse gestation, Psg mRNA expression is comprised almost entirely of Psg22 expressed in trophoblast giant cells (Blois et al., 2012, Wynne et al., 2006); however, a subset of Psg mRNAs are highly expressed in spongiotrophoblast during the second half of mouse gestation, with Psg16, Psg21 and Psg23 mRNAs being particularly abundant (Ball et al., 2004, Kromer et al., 1996, Wynne et al., 2006). Given the large number of PSG genes in the human, and the evidence of rapid evolution at this locus (Chang et al., 2013, Dumont et al., 2013), the PSG expression pattern appears remarkably constant in individual samples: in a series of placental samples from two male and two female pregnancies, PSG1 and PSG3 comprised the bulk of expression at the end of the first trimester, whereas PSG1, PSG3, PSG4, PSG5, and PSG6 were approximately equally expressed at term, with relatively low expression of the other PSGs (Shanley et al., 2013). Human PSG transcripts and proteins increase in trophoblast cells undergoing differentiation (Aronow et al., 2001, Camolotto et al., 2010). However, reports that PSGs are secreted by cultured human preimplantation embryos must be questioned given the apparent absence of PSG 
transcripts in recent RNA-seq datasets from preimplantation-stage human embryos (Dimitriadou et al., 1992, T. Moore \& K. Niakan, unpublished observations). We suggest that the antibodies used in some early studies of PSG expression may not have been specific to PSGs and that expression commences with the differentiation of syncytiotrophoblast as suggested by studies involving in vitro differentiation of cytotrophoblasts and the JEG-3 cell line (Aronow et al., 2001, Camolotto et al., 2010).

There is some evidence for PSG expression in non-trophoblastic tissues; however, much of the older literature may over-estimate the extent of PSG expression in adult tissues due to technical issues such as use of poorly validated antibodies, or reporting of rare or aberrant transcripts from cDNA libraries.

Conversely, a more recent study reported up-regulation of PSG9 expression in colorectal carcinogenesis (Salahshor et al., 2005), and using a panel of novel well characterized monoclonal antibodies to PSG1, PSG expression was found in intestinal epithelium (T. Moore \& colleagues, unpublished observations).

Mouse Psg17, Psg18 and Psg19 mRNAs were found using RTPCR in the placenta and in pooled tissues of embryonic, but not in adult, tissues (Kromer et al., 1996). However, Psg18 mRNA and protein were subsequently found in the follicle-associated epithelium overlaying intestinal Peyer's patches in the mouse (Kawano et al., 2007), and a brain-specific transcript of Psg16 has been reported (Phillips et al., 2012), suggesting that some PSGs may have evolved specific functions in adult tissues.

\section{PSG gene transcriptional regulation}

Relatively little is known about regulation of PSG expression. The region upstream of the PSG5 gene transcriptional start site has been characterized and, given the similarity to the paralogous region of other PSG genes, these studies may be applicable to understanding regulation of the entire family (Blanchon et al., 2006, Chamberlin et al., 1994, Nores et al., 2004). The human PSGgene promoters lack an obvious TATA box, typical initiator elements, or GC-rich regions (Frangsmyr et al., 2000, Panzetta-Dutari et al., 1992). PSG5 expression depends on a ubiquitous specificity protein 1 (Sp1) binding site located in the minimal core promoter region of all human $P S G$ s. This SP1 site activates PSG5 promoter constructs, and SP1 is co-expressed with PSGs in the syncytiotrophoblast (Nores et al., 2004). Using PSG5 promoter-reporter transfections and ChIP assays, Kruppel-like factor 4 (KLF4) was shown to be an activator of the PSG5 promoter by binding to a consensus site in the core promoter (Blanchon et al., 2006). Kruppel-like factor 6 (KLF6) was shown to activate PSG3 and PSG5 gene promoters in JEG-3 cells, further supporting an important role for the KLF family of transcription factors in PSG gene regulation (Racca et al., 2011). Additionally, a retinoic acid response element (RARE) /CACCC box composite element is highly conserved in the core promoters of all human $P S G$ genes. Consistent with a role for this element in PSG expression, it was shown that RXR $\alpha$ binds the PSG5 core promoter and 9-cis retinoic acid (RA) induces PSG5 expression in JEG-3 cells (Lopez-Diaz et al., 2007). Similarly, a RARE site in the PSG3 promoter was shown to be required for basal promoter activity using reporter assays (Camolotto et al., 2010). These observations are consistent with the known roles for retinoic acid (RA) derivatives and their receptors (RAR and RXR) in placental development (Sapin et al., 1997, Yan et al., 2001).
The PSG3 promoter also contains a putative binding site for the Ets family transcription factor GA-binding protein (GABP). This binding site was shown to be involved in PSG3 gene activation during trophoblast differentiation (Camolotto et al., 2010). Another Ets family member (PEA3) is similarly implicated in expression of multiple human PSGs (Chamberlin et al., 1994).

It has been suggested that PSG5, and presumably all PSGs by extrapolation, may be regulated by release from transcriptional repression. The PSG5 core promoter drives transcription in a reporter assay in a variety of cell types and tissue-specific expression may be mediated by repressive factors binding further upstream from the transcriptional start site (Panzetta-Dutari et al., 2000). Interestingly, induction of replicative senescence in HeLa cells by treatment with 5-bromodeoxyuridine resulted in upregulation of all PSGs; likewise, in normal human fibroblasts undergoing replicative senescence (Minagawa et al., 2005, Endoh et al., 2009). We suggest that replicative senescence may mimic aspects of terminally differentiated trophoblast cell lineages such as the syncytiotrophoblast thereby resulting in PSG expression.

The transcriptional regulation of mouse $P s g$ genes is virtually unexplored. However, both Ceacam and Psg gene expression is greatly attenuated in the placentas of Inositol requiring enzyme-1a (IRE1a) and X-box binding protein 1 (XBP1) knockout mice, which are implicated in endoplasmic reticulum (ER) stress responses and in placental development (Oikawa et al., 2010). Treatment of SM10 trophoblast cells with thapsigargin, an ER stressor that activates the IRE1a-XBP1 pathway, or overexpression of wild type IRE1a or XBP1, upregulated both Psg18 and Psg28. Use of Psg28 promoter deletion constructs identified two regions whose deletion reduced this response, but specific binding sites for XBP1 binding sites were not identified (Oikawa et al., 2010).

\section{PSG receptors}

While the cellular receptors for all members of the PSG family have yet to be identified, some progress has been made in the identification of the moieties that bind PSGs on the cell surface for some murine PSGs and for human PSG1. Murine PSG17 and PSG19 bind to CD9 (Ha et al., 2008, Waterhouse et al., 2002). CD9 is a member of the tetraspanin family, which consists of four transmembrane domains delimiting two extracellular loops or domains (Charrin et al., 2009). Over thirty different tetraspanins have been identified in humans and mouse. So far, the only interaction between the PSG and tetraspanin families that has been described is that of murine PSG17 and PSG19 with the extracellular domain 2 of CD9 (Ellerman et al., 2003). At this time, we have found no evidence for an interaction between mouse PSG22 and PSG23 or human PSG1 with CD9 but whether other members of the PSG family interact with CD9 or other tetraspanins remains to be explored. Expression of CD9 in macrophages was required for the ability of a protein consisting of the N-terminal domain of PSG17 to induce the secretion of cytokines by these cells, indicating that the PSG17-CD9 interaction has physiological consequences ( $\mathrm{Ha}$ et al., 2005).

Recently, human PSG1 and murine PSG17, PSG22 and PSG23 were shown to interact with heparan sulfate (Blois et al., 2012, Lisboa et al., 2011, Sulkowski et al., 2011). These interactions were demonstrated in solid phase assays, by affinity chromatography and in FACS analysis using Chinese hamster ovary $(\mathrm{CHO})$ cells 
lacking surface expression of the glycosaminoglycans (GAGs) heparin or chondroitin sulfate. In addition, these PSGs bound to the pre-B cell line Namalwa only when the cell line was transfected with syndecans or glypican-1, cell surface proteins which contain GAG chains. (Lisboa et al., 2011). Recently, we also determined that human PSG9 binds to syndecan-transfected Namalwa cells but not to the parental cell line, indicating that like PSG1 and murine PSGs-17, 22 and 23, PSG9 binds to GAGs (Dveksler, unpublished data).

Besides binding to heparan and chondroitin sulfate, recent studies indicate that PSG1 interacts with members of the integrin family. The tripeptide sequence Arg/Gly/Asp (RGD) found in the $\mathrm{N}$ domain of most human PSGs led to the suggestion that PSGs, similar to snake venom disintegrins, might bind integrins and disrupt cell - extracellular matrix interactions or modify other integrin-mediated functions, thereby facilitating trophoblastic invasion of maternal tissues (Rutherfurd et al., 1995). The disintegrin hypothesis was supported by an evolutionary analysis suggesting conservation of RGD-like tri-peptides at the homologous position of mouse Psg N1 domains (McLellan et al., 2005b).

Specifically, mouse Psg N1 domains do not possess an RGD tri-peptide motif, but do contain RGD-like motif sequences, which are not found in the N2 and N3 domains (Rudert et al., 1992, McLellan et al., 2005b). Additionally, PSG1 contains a KGD tripeptide motif overlapping, but one residue out of phase, with the 'RGD' position, suggesting an analogy to the snake venom disintegrin barbourin, which is a specific inhibitor of fibrinogen binding to the $\alpha \mathrm{llb} \beta 3$ integrin on platelets mediated by a KGD motif (Scarborough et al., 1991). All PSGs tested (PSG1, PSG9, and mouse Psg23) inhibited platelet - fibrinogen interactions suggesting an anti-thrombotic function for PSGs (Shanley et al., 2013). PSG1 binding to integrin $\alpha \mathrm{llb} \beta 3$ does not result in signaling indicating that the sole function of PSG binding appears to be inhibition of fibrinogen binding (Shanley et al., 2013). However, the mode of binding of PSG1 to the integrin is complex and mutation of the KGD sequence or deletion of the entire $\mathrm{N}$ domain did not abolish this function, suggesting that more than one of the PSG1 protein domains can independently mediate binding (Shanley et al., 2013).

Preliminary studies from the Dveksler laboratory indicate that $\beta 1$ integrin mediates the adhesion of endothelial cells and a trophoblast cell line (HTR-8) to PSG1-coated wells. Several members of the integrin family including $\alpha 5 \beta 1, \alpha v \beta 3$ and $\alpha \mathrm{llb} \beta 3$ are involved in modulation of trophoblast migration, invasion and adhesion and also regulate the interaction of endovascular trophoblasts with endothelial cells (Harris et al., 2009, Rout et al., 2004). Further studies are required to identify the integrin $\alpha$ chain, which together with the $\beta 1$ integrin subunit is involved in the adhesion to PSG1 and the physiological relevance of this interaction. Other human PSGs could potentially interact with integrins, which has been hypothesized based on the presence of an RGD tripeptide sequence in the $\mathrm{N}$-domain of some human PSGs with the exception of PSG1, 4 and 8. At this time, however, there is no evidence for an interaction of the $\mathrm{N}$-terminal domain of the RGD-containing PSGs with integrins. Furthermore, we have no evidence that the $\mathrm{N}$-terminal domain is involved in the PSG1$\beta 1$ integrin interaction, which was observed with recombinant PSG1 composed of all 4 domains as well as the recombinant protein containing just 3 domains ( $N, A 2$, and $B 2$ ).

\section{PSGs and angiogenesis}

The success of pregnancy in mammals relies on the spatiotemporal coordination of several vascular processes at the fetalmaternal interface. During normal pregnancy, increased placental blood flow is critical for fetal growth and survival. This increased blood flow results from angiogenesis, vasodilatation, and vascular remodeling. Placental trophoblasts are key regulators of placental endothelial functions. We found that PSG1 and murine PSG22 and PSG23 induced endothelial tube formation on Matrigel and type I collagen. Enzymatic removal of GAGs from the surface of endothelial cells negated the ability of PSG1 to induce tube formation demonstrating the importance of the PSG1-heparan/ chondroitin sulfate interaction. On the other hand, endothelial cells lacking the Vascular endothelial growth factor (VEGF) kinase insert domain receptor formed tubes in response to PSG1 treatment indicating that VEGF signaling is not required for the response to PSG1 (Lisboa et al., 2011). While PSG22 and PSG23 also induce endothelial tubulogenesis and bind to GAGs, the requirement for the interaction of these PSGs with GAGs for tube formation has not been studied (Blois et al., 2012 and G. Dveksler, unpublished data). In addition, whether PSG17 or other PSGs can induce the formation of tubes by endothelial cells remains unknown. VEGF$A$ is a key mediator in vasculogenesis and angiogenesis (Ferrara and Davis-Smyth, 1997). TGF- $\beta 1$ has been shown to regulate the production of VEGF-A (Jeon et al., 2007, Pertovaara et al., 1994). We found that PSG1 treatment of human extravillous trophoblast cell lines and primary monocytes resulted in an increase of VEGF-A secretion (Ha et al., 2010). The PSG1-mediated increase in VEGF secretion was mediated by TGF- $\beta$ since a neutralizing Ab to TGF- $\beta$ inhibited VEGF secretion from PSG1-treated extravillous trophoblast cells. Therefore at least some PSGs have pro-angiogenic properties which are mediated by two different mechanisms; the TGF- $\beta$-mediated induction of VEGF-A, and the direct interaction of PSGs with GAGs on the surface of endothelial cells.

The contribution of the PSG1-integrin $\beta 1$ interaction in the proangiogenic activity of this protein remains to be investigated as endothelial cells express high levels of this integrin.

\section{PSGs and TGF- $\beta$}

A relationship between PSGs and TGF- $\beta$ was first described in vitro by the Dveksler laboratory (Snyder et al., 2001). Treatment of human monocytes with recombinant PSG1, PSG6, and PSG11 generated in insect cells induced the secretion of TGF- $\beta 1$ in a dose-dependent manner. In addition, a protein composed of the N-terminal domain of PSG17, PSG17N, generated in insect or $\mathrm{CHO}-\mathrm{K} 1$ cells and purified following SDS-PAGE electrophoresis under denaturing conditions, was also shown to induce the secretion of TGF- $\beta 1$ by murine bone marrow derived macrophages and the murine macrophage cell line RAW 264.7 (Ha et al., 2005). Subsequent studies using other preparations of recombinant PSGs, including PSG1 composed of the N-A2-B2 domains fused to the FLAG, V5 and His tags (PSG1-FLAG-V5- His) or to the FC portion of the IgG1 heavy chain (PSG1-Fc), and two murine PSGs composed of the N1 and A-domains fused to the His and FLAG tags (PSG22N1A-His-FLAG and PSG23N1A-His-FLAG) were shown to induce the secretion of TGF- $\beta 1$ by several cells including dendritic cells, extravillous trophoblast cell lines, endothelial cells 
and NK cells (Blois et al., 2012, Ha et al., 2010, Wu et al., 2008).

Recently, we found that recombinant PSG1-Fc, PSG1-FLAGV5-His, murine PSG22N1A-His-FLAG and PSG23N1A-His-FLAG purified from the supernatant of transfected $\mathrm{CHO}-\mathrm{K} 1$ cells are associated with TGF- $\beta 1$, which is normally produced by this cell line (Blois et al., 2013; G.Dveksler, unpublished results). Therefore, while it is still possible that these PSGs induce TGF- $\beta 1$ in the cells listed above, new experiments should be performed with preparations of these proteins lacking associated TGF- $\beta 1$ before a definitive conclusion can be reached regarding their ability to induce the secretion of this cytokine.

Importantly, proteins generated in insect cells or after separation by SDS-PAGE do not have associated TGF- $\beta 1$, indicating that the initial reports on the ability of some human PSGs and PSG17N to induce TGF- $\beta 1$ are not compromised by our recent discovery.

Since native PSG1 purified from the serum of pregnant women and recombinant PSG1 were both shown to associate with TGF$\beta 1$, we asked whether PSG1 is a novel TGF $-\beta 1$ binding protein and whether it has the potential to activate latent TGF- $\beta$. Most cells secrete at least one TGF- $\beta$ isoform (TGF- $\beta 1,-2$ and -3 ) in the non-biologically active/latent form (Annes et al., 2003). The non-covalent interaction of mature TGF- $\beta$ with the isoform-specific latency-associated peptide (LAP) blocks binding of mature TGF$\beta$ s to the specific receptors. Therefore activation of latent TGF- $\beta$ requires agents that disrupt the association of LAP with the mature domain either by cleaving LAP or by altering its conformation (Shi et al., 2011). An experimental approach employing a cell-free system indicated that PSG1 is able to activate the small latent complex (SLC) of TGF- $\beta 1$ in a dose-dependent manner (Blois et al., 2013). Because the small latent form of TGF- $\beta 2$ is not commercially available, reporter assays were used and strongly suggested that PSG1 can also activate this isoform (Blois et al., 2013). Whether PSG1 can activate the latent TGF- $\beta 3$ isoform remains to be investigated. The Dveksler laboratory is currently testing whether other members of the human PSG family share with PSG1 the ability to activate TGF- $\beta 1$ and TGF $\beta-2$.

The increased availability of biologically active TGF- $\beta$ mediated by PSG1 administration has biological consequences in vivo. Administration of PSG1 protected mice from dextran sulfate induced colitis and the observed protective effect of PSG1 was inhibited by co-administration of a neutralizing anti-TGF- $\beta$ antibody (Blois et al., 2013). PSG1-treated mice expressed lower levels of the pro-inflammatory cytokines TNF- $\alpha$ and IFN- $\gamma$ compared to protein control- treated mice. In addition, mice receiving PSG1 had increased numbers of FoxP3+ LAP + regulatory T cells (Tregs) in the colonic lamina propria. An increase in the number of Tregs upon PSG1 administration was also observed in a different in vivo experimental system. Mice injected with a vaccinia virus expressing PSG1 and challenged with Listeria monocytogenes had expanded numbers of CD25+ Foxp3+ cells when compared to vaccinia virus control-treated mice (Martinez et al., 2012). We and others found that conditioned media obtained from the extravillous trophoblast cell line HTR- 8 contains the active form of TGF- $\beta$ (Graham and Lala, 1991). The mechanism by which TGF- $\beta$ is activated in the media of these cells remains unknown but HTR-8 cells express PSG $m R N A$ and PSG1 can be detected in the supernatant of these cells by ELISA (G. Dveksler, unpublished data). Therefore, it is possible that the reported HTR-8-mediated induction of inducible Tregs is associated with the production of PSG1 by this cell line
(Ramhorst et al., 2012).

The actions of PSG1 on cells of the innate and adaptive immune system have been recently reviewed in (Martinez et al., 2013). IL-10 and TGF- $\beta$ are suppressor cytokines, which are interrelated (Kitani et al., 2003, Li et al., 2006, Moore et al., 2001). PSG1 has been shown to induce the secretion of IL-10 and the alternative activation of macrophages (Motran et al., 2002). Whether these PSG1 functions and the reported modulation of dendritic cell maturation by PSG1 are a result of its newly discovered ability to activate TGF- $\beta$ remains to be elucidated (Martinez et al., 2012). In addition, while some of the reported activities of human PSG1, -6 and -11 such as the ability to induce the secretion of IL-10 and IL- 6 by monocytes, have also been reported for murine PSG17; the mechanism and signaling pathways behind the responses to human PSGs have not been elucidated and may differ from the signaling events involved in the response to murine PSGs, as different receptors and/or signaling mechanisms may have evolved separately resulting in similar functions (Ha et al., 2005, Snyder et al., 2001, Wessells et al., 2000).

\section{PSGs and pregnancy pathologies}

Several reports indicate that lower than normal serum concentrations of PSGs are associated with fetal growth restrictions (Grudzinskas et al., 1983, Pihl et al., 2009, Salem et al., 1981, Towler et al., 1977, Wurz et al., 1981). In addition, a correlation between abnormally low PSG levels and preeclampsia was found in some studies but not others (Bersinger and Odegard, 2004, Pihl et al., 2009, Silver et al., 1993, Towler et al., 1977). A critical evaluation of the published studies on the association of PSG levels and pregnancy complications is required based on the complexity of the CEACAM/PSG family. First, all measurements of PSGs reported in the cited publications were performed with polyclonal anti-PSG antibodies incapable of differentiating between the different gene products and the measurements of PSG levels sometimes differ in the trimester of pregnancy at which they were conducted. In addition, in vitro studies using sequence specific primers for different $P S G$ family members indicate that $P S G$ sare expressed at different levels (Camolotto et al., 2010), which is supported by differences in the promoter sequences (Chamberlin et al., 1994). Therefore measuring the concentration of all PSGs may not accurately reflect a possible association of abnormal concentrations of some members of the family with pregnancy pathology. Adding to these complications, is new information indicating that there is a big range of what may be considered "normal PSG levels". PSG gene copy numbers are polymorphic in the human population and they range from 12 to 30 in normal individuals (Chang et al., 2013). Recently, Dewan and co-workers reported that a copy-number deletion of PSG11 and its alternatively spliced variants may confer risk for preeclampsia but further studies are required to confirm their findings (Zhao et al., 2012). Expression of some PSGs has been reported in molar trophoblastic tissue (Hagiwara et al., 1986, Leslie et al., 1990) and differential expression of PSGs in intrauterine pregnancy and ectopic pregnancy have been recently suggested to have useful diagnostic value as part of a multiple biomarker test (Rausch et al., 2011). In summary, while low PSG concentrations appear associated with some pregnancy complications, studies with more specific reagents are required as PSG levels could potentially be used as useful markers of placental function. 


\section{Conclusions}

Further studies are required to understand the functions and characterize the receptors and modes of action of the different PSGs expressed in humans, non-human primates, and rodents. In addition, the recently discovered association between PSG1 and TGF- $\beta$ suggests that PSGs may play a role in the well-established beneficial effects of pregnancy in patients suffering from autoimmune diseases such as multiple sclerosis and rheumatoid arthritis. This indicates that administration of PSG1 should be explored as a novel therapeutic agent in diseases related to undesired immune activation in non-pregnant individuals.

\section{Acknowledgements}

Research reported in this publication was supported by the National Institute of Allergy and Infectious Diseases of the National Institutes of Health under Award Number R21Al101979. The content is solely the responsibility of the authors and does not necessarily represent the official views of the National Institutes of Health or the Department of Defense.

\section{References}

ANNES JP, MUNGER JS, RIFKIN DB (2003). Making sense of latent TGFbeta activation. J Cell Sci 116: 217-224.

ARONOW BJ, RICHARDSON BD, HANDWERGER S (2001). Microarray analysis of trophoblast differentiation: gene expression reprogramming in key gene function categories. Physiol Genom 6: 105-116.

BALLM, MCLELLANA, COLLINSB, COADWELLJ, STEWARTF, MOORET(2004). An abundant placental transcript containing an IAP-LTR is allelic to mouse pregnancyspecific glycoprotein 23 (Psg23): cloning and genetic analysis. Gene 325: 103-113.

BERSINGER NA, ODEGARD RA (2004). Second- and third-trimester serum levels of placental proteins in preeclampsia and small-for-gestational age pregnancies. Acta Obstet Gynecol Scand 83: 37-45.

BLANCHON L, NORES R, GALLOT D, MARCEAU G, BOREL V, YANG VW, BOCCO JL, LÉMERY D, PANZETTA-DUTARI G, SAPIN V (2006). Activation of the human pregnancy-specific glycoprotein PSG-5 promoter by KLF4 and Sp1. Biochem Biophys Res Commun 343: 745-753.

BLOIS S, TIRADO-GONZALEZ I, WU J, BARRIENTOS G, JOHNSON B, WARREN J, FREITAG N, KLAPP BF, IRMAK S, ERGUN S, DVEKSLER GS (2012). Early Expression of Pregnancy-Specific Glycoprotein 22 (PSG22) by Trophoblast Cells Modulates Angiogenesis in Mice. Biol Reprod 86: 1-9.

BLOISSM, SULKOWSKI G, TIRADO-GONZALEZI, WARREN J, FREITAG N, KLAPP BF, RIFKIN D, FUSS I, STROBER W, DVEKSLER, GS (2013). Pregnancy-specific glycoprotein 1 (PSG1) activates TGF-beta and prevents dextran sodium sulfate (DSS)-induced colitis in mice. Mucosal Immunol. DOI:10.1038/mi.2013.53

CAMOLOTTO S, RACCA A, RENA V, NORES R, PATRITO LC, GENTI-RAIMONDI S, PANZETTA-DUTARI GM (2010). Expression and transcriptional regulation of individual pregnancy-specific glycoprotein genes in differentiating trophoblast cells. Placenta 31: 312-319.

CHAMBERLIN ME, LEI KJ, CHOU J.Y(1994). Subtle differences in human pregnancyspecific glycoprotein gene promoters allow for differential expression. J Biol Chem 269: 17152-17159.

CHANG CL, SEMYONOV J, CHENG PJ, HUANG SY, PARK JI, TSAI HJ, LIN CY, GRÜTZNER F, SOONG YK, CAI JJ, HSU SY (2013). Widespread Divergence of the CEACAM/PSG Genes in Vertebrates and Humans Suggests Sensitivity to Selection. PLoS One 8: e61701.

CHARRIN S, LE NAOUR F, SILVIE O, MILHIET PE, BOUCHEIX C, RUBINSTEIN E (2009). Lateral organization of membrane proteins: tetraspanins spin their web. Biochem J 420: 133-154.

DUMONT BL, EICHLER EE (2013). Signals of Historical Interlocus Gene Conversion in Human Segmental Duplications. PLoS One 8: e75949.

DIMITRIADOU F, PHOCAS I, MANTZAVINOS T, SARANDAKOU A, RIZOS D, ZOURLAS PA (1992). Discordant secretion of pregnancy specific beta 1-glycoprotein and human chorionic gonadotropin by human pre- embryos cultured in vitro. Fertil Steril 57: 631-636.

ELLERMAN DA, HA C, PRIMAKOFF P, MYLES DG, DVEKSLER GS (2003). Direct binding of the ligand PSG17 to CD9 requires a CD9 site essential for sperm-egg fusion. Mol Biol Cell 14: 5098-5103.

ENDOH M, KOBAYASHI Y, YAMAKAMI Y, YONEKURA R, FUJII M, AYUSAWA D (2009). Coordinate expression of the human pregnancy-specific glycoprotein gene family during induced and replicative senescence. Biogerontology 10: 213-221.

FERRARA N, DAVIS-SMYTH T (1997). The biology of vascular endothelial growth factor. Endocr Rev 18: 4-25.

FRANGSMYR L, ISRAELSSON A, TEGLUND S, MATSUNAGA T, HAMMARSTRÖM $S$ (2000). Evolution of the carcinoembryonic antigen family. structures of CGM9, CGM11 and pregnancy-specific glycoprotein promoters. Tumour Biol 21: 63-81.

GRAHAM CH, LALA PK (1991). Mechanism of control of trophoblast invasion in situ. J Cell Physiol 148: 228-234.

GRUDZINSKAS JG, GORDON YB, MENABAWEY M, LEE JN, WADSWORTH J,CHARD T (1983). Identification of high-risk pregnancy by the routine measurement of pregnancy-specific beta 1-glycoprotein. Am J Obstet Gynecol 147: 10-12.

HA CT, WATERHOUSE R, WARREN J, ZIMMERMANN W, DVEKSLER GS (2008). $\mathrm{N}$-glycosylation is required for binding of murine pregnancy-specific glycoproteins 17 and 19 to the receptor CD9. Am J Reprod Immunol 59: 251-258.

HA CT, WATERHOUSE R, WESSELLS J, WU JA, DVEKSLER GS (2005). Binding of pregnancy-specific glycoprotein 17 to $\mathrm{CD} 9$ on macrophages induces secretion of IL-10, IL-6, PGE2, and TGF-beta1. J Leukoc Biol 77: 948-957.

HACT, WU JA, IRMAKS, LISBOAFA, DIZONAM, WARRENJ, ERGUNS, DVEKSLER GS (2010). Human pregnancy specific beta-1-glycoprotein 1 (PSG1) has a potential role in placental vascular morphogenesis. Biol Reprod 83: 27-35.

HAGIWARA K, KOBAYASHI K, KAJII T (1986). Serum proteins in vesicular fluid of hydatidiform moles: a lack of selectivity of molar trophoblast in the transfer of maternal serum proteins. Placenta 7: 199-207.

HAMMARSTRÖM S (1999). The carcinoembryonic antigen (CEA) family: structures, suggested functions and expression in normal and malignant tissues. Sem Cancer Biol 9: 67-81.

HARRIS LK, JONES CJ, APLIN JD (2009). Adhesion molecules in human trophoblast - a review. II. extravillous trophoblast. Placenta 30: 299-304.

HUANG J, LEDFORD KJ, PITKIN WB, RUSSO L, NAJJAR SM, SIRAGY HM (2013). Targeted deletion of murine CEACAM 1 activates PI3K-Akt signaling and contributes to the expression of (Pro)renin receptor via CREB family and NF-KB transcription factors. Hypertension 62: 317-323.

JEON SH, CHAE BC, KIM HA, SEO GY, SEO DW, CHUN GT, KIM NS, YIE SW, BYEON WH, EOM SH, HA KS, KIM YM, KIM PH (2007). Mechanisms underlying TGF-beta1-induced expression of VEGF and Flk-1 in mouse macrophages and their implications for angiogenesis. J Leukoc Biol 81: 557-566.

KAMMERER R, ZIMMERMANN W (2010). Coevolution of activating and inhibitory receptors within mammalian carcinoembryonic antigen families. BMC Biol 4: 12 .

KAWANO K, EBISAWA M, HASE K, FUKUDA S, HIJIKATA A, KAWANO S, DATE Y, TSUNEDA S, ITOH K, OHNO H (2007). Psg18 is specifically expressed in follicleassociated epithelium. Cell Struct Funct 32: 115-126.

KITANIA, FUSSI, NAKAMURAK, KUMAKIF, USUIT, STROBERW (2003). Transforming growth factor (TGF)-beta1-producing regulatory T cells induce Smad-mediated interleukin 10 secretion that facilitates coordinated immunoregulatory activity and amelioration of TGF-beta1-mediated fibrosis. J Exp Med 198: 1179-1188.

KROMER B, FINKENZELLER D,WESSELLS J, DVEKSLER G, THOMPSON J, ZIMMERMANN W (1996). Coordinate expression of splice variants of the murine pregnancy-specific glycoprotein (PSG) gene family during placental development. Eur J Biochem / FEBS 242: 280-287.

KUESPERT K, PILS S, HAUCK CR (2006). CEACAMs: their role in physiology and pathophysiology. Curr Opin Cell Biol 18: 565-571.

LEE JN, GRUDZINSKAS JG, CHARD T (1979). Circulating levels of pregnancy proteins in early and late pregnancy in relation to placental tissue concentration. BJOG 86: 888-890.

LESLIE KS, WATANABE S, LEI KJ, CHOU DY, PLOUZEK CA, DENG HC, TORRES J, CHOU JY (1990). Linkage of two human pregnancy-specific beta 1-glycoprotein genes: one is. Proc Natl Acad Sci U S A 87: 5822-5826. 
LI MO, SANJABI S,FLAVELL RA (2006). Transforming growth factor-beta controls development, homeostasis, and tolerance of $T$ cells by regulatory $T$ cell-dependent and -independent mechanisms. Immunity 25: 455-471.

LIN T, HALBERT S, SPELLACY W (1974). Measurement of pregnancy-associated plasma proteins during human gestation. $\mathrm{JCl}$ 54: 576-582.

LIN TM, GALBERT SP, KIEFER D, SPELLACY WN, GALL S (1974). Characterization of four human pregnancy-associated plasma proteins. Am J Obstet Gynecol 118: 223-236.

LISBOA FA, WARREN J, SULKOWSKI G, APARICIO M, DAVID G, ZUDAIRE E, DVEKSLER GS (2011). Pregnancy-specific glycoprotein 1 induces endothelial tubulogenesis through interaction with cell surface proteoglycans. $J$ Biol Chem 286: 7577-7586.

LÓPEZ-DÍAZ F, NORES R, PANZETTA-DUTARI GM, SLAVIN D, PRIETO C, KORITSCHONERNP, BOCCOJL(2007). RXRalpha regulates the pregnancy-specific glycoprotein 5 gene transcription through a functional retinoic acid responsive element. Placenta 28(8-9): 898-906.

MARTINEZFF, CERVIL, KNUBELCP, PANZETTA-DUTARI GM, MOTRANCC (2013). The role of pregnancy- specific glycoprotein $1 a$ (PSG1a) in regulating the innate and adaptive immune response. Am J Reprod Immunol 69: 383-394.

MARTINEZFF, KNUBELCP, SANCHEZMC, CERVIL, MOTRANCC (2012). Pregnancyspecific glycoprotein 1a activates dendritic cells to provide signals for Th17-, Th2-, and Treg-cell polarization. Eur J Immunol 42: 1573-1584.

MCLELLANAS, FISCHER B, DVEKSLER G, HORIT, WYNNE F, BALL M, OKUMURA K, MOORE T, ZIMMERMANN W (2005a). Structure and evolution of the mouse pregnancy-specific glycoprotein (Psg) gene locus. BMC Genomics 6: 4.

MCLELLAN AS, ZIMMERMANN W, MOORE T (2005b). Conservation of pregnancyspecific glycoprotein (PSG) N domains following independent expansions of the gene families in rodents and primates. BMC Evol Biol 5: 39.

MINAGAWA S, NAKABAYASHI K, FUJII M, SCHERER SW, AYUSAWA D (2005). Early BrdU-responsive genes constitute a novel class of senescence-associated genes in human cells. Exp Cell Res 304: 552-558.

MOORE KW, DE WAAL MALEFYT R, COFFMAN RL, O'GARRA A (2001). Interleukin-10 and the interleukin-10 receptor. Annu Rev Immunol 19: 683-765.

MOTRAN CC, DIAZ FL, GRUPPI A, SLAVIN D, CHATTON B, BOCCO JL (2002). Human pregnancy-specific glycoprotein 1a (PSG1a) induces alternative activation in human and mouse monocytes and suppresses the accessory cell-dependent $T$ cell proliferation. J Leukoc Biol 72: 512-521.

NORES R, BLANCHON L, LÓPEZ-DÍAZ F, BOCCO JL, PATRITO LC, SAPIN V, PANZETTA-DUTARI GM (2004). Transcriptional control of the human pregnancyspecific glycoprotein 5 gene is dependent on two GT- boxes recognized by the ubiquitous specificity protein 1 (Sp1) transcription factor. Placenta 25: 9-19.

OBRINK B (1997). CEA adhesion molecules: multifunctional proteins with signalregulatory properties. Curr Opin Cell Biol 9: 616-626.

OIKAWA D, AKAI R, IWAWAKI T (2010). Positive contribution of the IRE1alpha-XBP1 pathway to placental expression of CEA family genes. FEBS Lett. 584: 1066-1070.

PANZETTA-DUTARI GM, BOCCO JL, REIMUND B, FLURY A, PATRITO LC (1992). Nucleotide sequence of a pregnancy-specific beta 1 glycoprotein gene family member. Identification of a functional promoter region and several putative regulatory sequences. Mol Biol Rep 16: 255-262.

PANZETTA-DUTARI GM, KORITSCHONER N (2000). Transcription of genes encoding pregnancy-specific glycoproteins is regulated by negative promoter-selective elements. Biochem J 519: 511-519.

PERTOVAARAL, KAIPAINENA, MUSTONENT, ORPANAA, FERRARAN, SAKSELA O, ALITALO K (1994). Vascular endothelial growth factor is induced in response to transforming growth factor-beta in fibroblastic and epithelial cells. J Biol Chem 269: 6271-6274.

PHILLIPS JM, KUO IT, RICHARDSON C,WEISS SR (2012). Anovel full-length isoform of murine pregnancy- specific glycoprotein 16 (psg16) is expressed in the brain but does not mediate murine coronavirus (MHV) entry. J Neurovirol 18: 138-143.

PIHLK, LARSEN T, LAURSEN I, KREBS L, CHRISTIANSEN M (2009). First trimester maternal serum pregnancy-specific beta-1-glycoprotein (SP1) as a marker of adverse pregnancy outcome. Prenat Diagn 29: 1256-1261.

RACCA AC, CAMOLOTTO S, RIDANO ME, BOCCO JL, GENTI-RAIMONDI S, PANZETTA-DUTARI GM (2011). Krüppel-Like Factor 6 Expression Changes during Trophoblast Syncytialization and Transactivates $\beta$ hCG and PSG Placental Genes. PloS One 6: e22438.
RAMHORST R, FRACCAROLI L, ALDO P, ALVEROA B, CARDENAS I, LEIROS CP, MOR G (2012). Modulation and recruitment of inducible regulatory $T$ cells by first trimester trophoblast cells. Am J Reprod Immunol 67: 17-27.

RAUSCH ME, SAMMEL MD, TAKACS P, CHUNG K, SHAUNIK A, BARNHART KT (2011). Development of a multiple marker test for ectopic pregnancy. Obstet Gynecol 117: 573-582.

ROUT UK, WANG J, PARIA BC, ARMANT DR (2004). Alpha5beta1, alphaVbeta3 and the platelet- associated integrin alphallbbeta3 coordinately regulate adhesion and migration of differentiating mouse trophoblast cells. Dev Biol 268: 135-151.

RUDERT F, SAUNDERS AM, REBSTOCK S, THOMPSON JA, ZIMMERMANN W (1992). Characterization of murine carcinoembryonic antigen gene family members. Mamm Genome 3: 262-273.

RUTHERFURD KJ, CHOU JY, MANSFIELD BC (1995). A motif in PSG11s mediates binding to a receptor on the surface of the promonocyte cell line THP-1. Mol Endocrinol 9: 1297-1305.

SALAHSHORS, GONCALVESJ, CHETTYR, GALLINGERS, WOODGETTJR(2005). Differential gene expression profile reveals deregulation of pregnancy specific beta1 glycoprotein 9 early during colorectal carcinogenesis. BMC cancer $5: 66$.

SALEM HT, LEE JN, SEPPALA M, VAARA L, AULA P, AL-ANI AT,CHARD T (1981). Measurement of placental protein 5, placental lactogen and pregnancy-specific beta 1 glycoprotein in mid-trimester as a predictor of outcome of pregnancy. $\mathrm{Br} \mathrm{J}$ Obstet Gynaecol 88: 371-374.

SAPIN V, DOLLÉ P, HINDELANG C, KASTNER P, CHAMBON P (1997). Defects of the chorioallantoic placenta in mouse RXRalpha null fetuses. Dev Biol 191: 29-41.

SCARBOROUGH RM, ROSE JW, HSU MA, PHILLIPS DR, FRIED VA, CAMPBELL AM, NANNIZZI L, CHARO IF (1991). Barbourin. A GPIIb-IIla-specific integrin antagonist from the venom of Sistrurus m. barbouri. J Biol Chem 266: 9359-9362.

SHANLEY DK, KIELY PA, GOLLA K, ALLEN S, MARTIN K, O'RIORDAN RT, BALL M, APLIN JD, SINGER BB, CAPLICE N, MORAN N, MOORE T (2013). Pregnancyspecific glycoproteins bind integrin $\alpha$ llb $\beta 3$ and inhibit the platelet-fibrinogen interaction. PLoS One 8: e57491.

SHI M, ZHU J, WANG R, CHEN X, MI L, WALZT,SPRINGER TA (2011). Latent TGFbeta structure and activation. Nature 474: 343-349.

SILVER RM, HEYBORNE KD, LESLIE KK (1993). Pregnancy specific beta 1 glycoprotein (SP-1) in maternal serum and amniotic fluid; pre-eclampsia, small for gestational age fetus and fetal distress. Placenta 14: 583-589.

SNYDER SK, WESSNER DH, WESSELLS JL, WATERHOUSE RM, WAHLL M, ZIMMERMANN W, DVEKSLER, GS (2001). Pregnancy-specific glycoproteins function as immunomodulators by inducing secretion of IL-10, IL-6 and TGF-beta1 by human monocytes. Am J Reprod Immunol 45: 205-216.

SULKOWSKI GN, WARRENJ, HACT, DVEKSLERGS (2011). Characterization of receptors for murine pregnancy specific glycoproteins 17 and 23. Placenta 32: 603-610.

TOWLER CM, HORNE CH, JANDIAL V, CAMPBELL DM, MACGILLIVRAY I (1977). Plasma levels of pregnancy-specific beta 1-glycoprotein in complicated pregnancies. Br J Obstet Gynaecol 84: 258-63.

WATERHOUSE R, HA C, DVEKSLER GS (2002). Murine CD9 is the receptor for pregnancy-specific glycoprotein 17. J Exp Med 195: 277-282.

WESSELLS J, WESSNER D, PARSELLS R, WHITE K, FINKENZELLER D, ZIMMERMANN W, DVEKSLER G (2000). Pregnancy specific glycoprotein 18 induces IL-10 expression in murine macrophages. Eur J Immunol 30: 1830-1840.

WU JA, JOHNSON BL, CHEN Y, HA CT, DVEKSLER GS (2008). Murine pregnancyspecific glycoprotein 23 induces the proangiogenic factors transforming-growth factor beta 1 and vascular endothelial growth factor a in cell types involved in vascular remodeling in pregnancy. Biol Reprod 79: 1054-1061.

WURZ H, GEIGER W, KUNZIG HJ, JABS-LEHMANN A, BOHN H, LUBEN G (1981). Radioimmunoassay of SP1 (pregnancy-specific beta1-glycoprotein) in maternal blood and in amniotic fluid normal and pathologic pregnancies. $J$ Perinat Med 9: 67-78.

WYNNE F, BALL M, MCLELLAN AS, DOCKERY P, ZIMMERMANN W, MOORE T (2006). Mouse pregnancy-specific glycoproteins: tissue-specific expression and evidence of association with maternal vasculature. Reproduction 131: 721-732.

YAN J, TANAKA S, ODA M, MAKINO T, OHGANE J, SHIOTA K (2001). Retinoic acid promotes differentiation of trophoblast stem cells to a giant cell fate. Dev Biol 235: 422-432.

ZEBHAUSER R, KAMMERER R, EISENRIED A, MCLELLAN A, MOORE T, ZIMMERMANN W (2005). Identification of a novel group of evolutionarily conserved 
members within the rapidly diverging murine Cea family. Genomics 86: 566-580. ZHAO L, TRICHE EW, WALSH KM, BRACKEN MB, SAFTLAS AF, HOH J, DEWANAT (2012). Genome-wide association study identifies a maternal copy-number deletion in PSG11 enriched among preeclampsia patients. BMCPregnancy Childbirth 12:61.
ZHOU GQ, BARANOV V, ZIMMERMANN W, GRUNERT F, ERHARD B, MINCHEVANILSSONL, HAMMARSTRÖMS, THOMPSONJ (1997). Highly specific monoclonal antibody demonstrates that pregnancy-specific glycoprotein (PSG) is limited to syncytiotrophoblast in human early and term placenta. Placenta 18: 491-501. 


\section{Further Related Reading, published previously in the Int. J. Dev. Biol.}

The interplay between macrophages and angiogenesis in development, tissue injury and regeneration Silvia Nucera, Daniela Biziato and Michele De Palma

Int. J. Dev. Biol. (2011) 55: 495-503

http://dx.doi.org/10.1387/ijdb.103227sn

Immunoregulatory molecules in human placentas: potential for diverse roles in pregnancy

Joan S. Hunt, Judith L. Pace and Ryan M. Gill

Int. J. Dev. Biol. (2010) 54: 457-467

http://dx.doi.org/10.1387/ijdb.082831jh

On the role of placental major histocompatibility complex and decidual leukocytes in implantation and pregnancy success using non-human primate models

Thaddeus G. Golos, Gennadiy I. Bondarenko, Svetlana V. Dambaeva, Edith E. Breburda, and Maureen Durning

Int. J. Dev. Biol. (2010) 54: 431-443

http://dx.doi.org/10.1387/ijdb.082797tg

Trophoblast phagocytic program: roles in different placental systems

Estela Bevilacqua, Mara-Sandra Hoshida, Andrea Amarante-Paffaro, Andrea Albieri-Borges and Sara Zago-Gomes

Int. J. Dev. Biol. (2010) 54: 495-505

http://dx.doi.org/10.1387/ijdb.082761eb

Developmental cell biology of human villous trophoblast: current research problems John D. Aplin

Int. J. Dev. Biol. (2010) 54: 323-329

http://dx.doi.org/10.1387/ijdb.082759ja

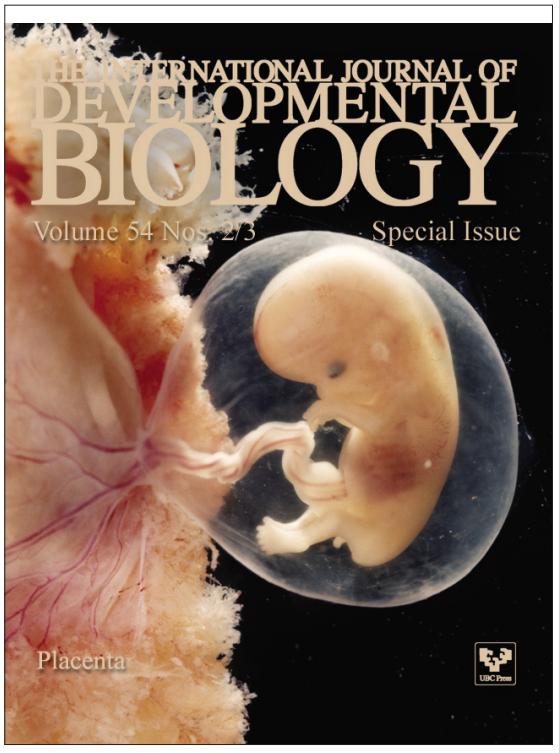

5 yr ISI Impact Factor $(2011)=2.959$

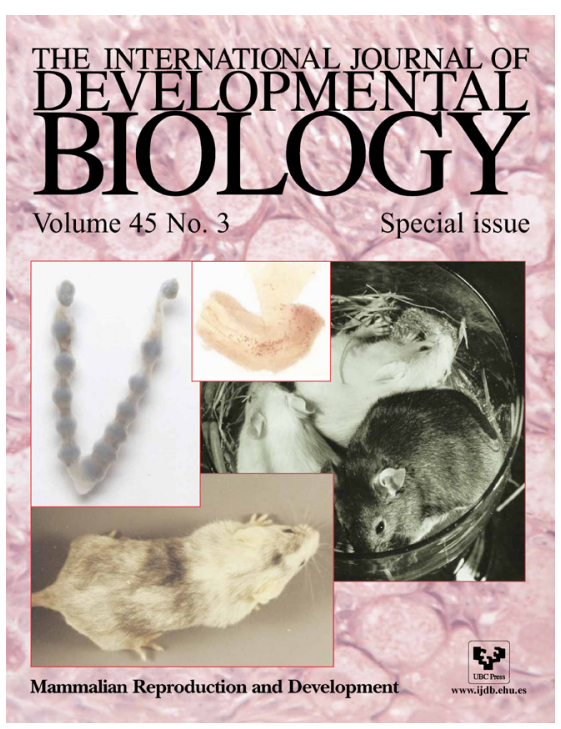

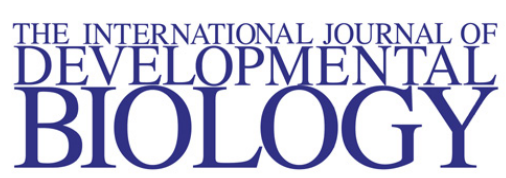

Volume 48 Nos. $5 / 6$

Special issue

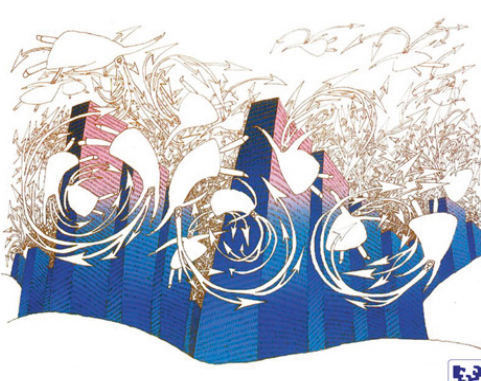

Invasion in cancer and embryonic development 